\title{
Urgences
}

\section{Des inscriptions...}

\section{Jocelyne Lévesque}

Numéro 15, octobre 1986

Épigraphiques

URI : https://id.erudit.org/iderudit/025355ar

DOI : https://doi.org/10.7202/025355ar

Aller au sommaire du numéro

Éditeur(s)

Urgences

ISSN

0226-9554 (imprimé)

1927-3924 (numérique)

Découvrir la revue

Citer ce document

Lévesque, J. (1986). Des inscriptions... Urgences, (15), 98-98. https://doi.org/10.7202/025355ar

Ce document est protégé par la loi sur le droit d'auteur. L'utilisation des services d'Érudit (y compris la reproduction) est assujettie à sa politique d'utilisation que vous pouvez consulter en ligne.

https://apropos.erudit.org/fr/usagers/politique-dutilisation/
Cet article est diffusé et préservé par Érudit.

Érudit est un consortium interuniversitaire sans but lucratif composé de l’Université de Montréal, l'Université Laval et l'Université du Québec à Montréal. Il a pour mission la promotion et la valorisation de la recherche. https://www.erudit.org/fr/ 


\section{Jocelyne Lévesque}

[...] publicité "strip-tease" s'installe sur nos murs. [...] panneaux [...] envahis [...] de messages "style Libé": d'une petite brune "aimant les contacts à plusieurs", d'une blonde ayant "besoin de rapports rapides et fréquents" [...] Jouant [...] sur les fantasmes des Français [...] l'agence [...] a imaginé pour son client [...] une campagne en faveur de la $[\ldots]$ bureautique.

Alain Woodrow: "Publicité = titiller", dans Le Monde (10-11 août 1986)

Des inscriptions, selon l'ordre de la PS. La vérité factice, en négatif/positif, toute nue ou presque, informe par cinquante-deux pour cent.

Sur les oreillers métalliques, le poseur d'affiches mouille la ville de séductions carrées. Comme une claque donnée, jamais reprise ni rendue, le fesse à face des concepteurs s'extrait des formes, parfois en

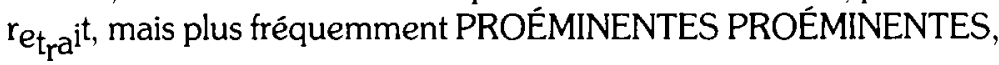
de la demie.

On enlève la chemise à une bière maternelle, souvenir, ici, du lait du même nom. Qui dit mieux? Simple, Satwon! Il faut doubler la mise et l'inverser. À la liberté, un deuxième sein franc et elle sera complètement américaine. Noire. La bouteille à la mer se fracasse sur les panneaux $\rightarrow$ on baptise une nouvelle PS, hors des murs de la secte qui l'a conçue. Soeur des autres. De mère en fille. Ou presque. Fille de pub. Tout sexe replié, la PS, tout sexe replié.

Les mains baissées et les yeux joints, des bandes fondent un peu à l'éphémère éternel des filles de pub. Les clients avoués ne paraissent jamais sceptiques. Quant à l'hésitant aseptisé ou moins touché, il pourra toujours "se connaître", dirions-nous dans un élan biblique.

Le présent est aux mots. Pour l'instant. Là, cause toujours! On cherche à dire en démontrant à demi, à défaut de laisser entendre en montrant ce qui n'est pas dit. Par définition, la politique de la PS ne sera jamais égalitaire. Par définition $\longrightarrow$ il faut bien que la culture, dont la publicité et le sexisme font partie, se ménage un prétexte.

L'encre noire lavera tout blanc pourvu que le sperme de Dieu soit respecté. 